\title{
The Relationship between Internet Use and Academic Procrastination of EFL Learners across Years of Study
}

\author{
Maryam Mohammadi (Corresponding author) \\ Department of English Language and Literature, University of Guilan, Rasht, Iran \\ E-mail: maryammohammadi_66@yahoo.com \\ Abdorreza Tahriri \\ Department of English Language and Literature, University of Guilan, Rasht, Iran \\ E-mail: atahriri@gmail.com \\ Jaleh Hassaskhah \\ Department of English Language and Literature, University of Guilan, Rasht, Iran \\ E-mail: jaleh_hassaskhah@yahoo.com
}

Received: 22-07-2014

doi:10.7575/aiac.ijalel.v.4n.1p.231
Accepted: 08-09-2014

Published: 01-01-2015

URL: http://dx.doi.org/10.7575/aiac.ijalel.v.4n.1p.231

\begin{abstract}
The present study aimed at exploring the relationship between Internet use and academic procrastination of a group of EFL learners across years of study (freshmen, sophomores, juniors, and seniors). The study was conducted in two phases. First, a pilot study was conducted among 30 representative university students in order to check the reliability and validity of the main instrument utilized, i.e. a questionnaire. After that, the piloted questionnaire was distributed among 380 undergraduates studying at the University of Guilan, Kharazmi University, and Ferdowsi University. Results of Spearman Rank Order Test at the .01 level of significance revealed a medium positive relationship (rho= +.47 ) between Internet use and academic procrastination of the participating students. Furthermore, the results of Kruskal Wallis Test at the significance level of .05 indicated that there is a significant difference in both Internet use $(\mathrm{sig}=.029, \mathrm{p} \leq .05)$ and academic procrastination $(\mathrm{sig}=.007, \mathrm{p} \leq .05)$ of learners across different years of study, with freshmen being the pioneer in this respect. However, the results of another Kruskal Wallis Test run on data concerning areas of academic procrastination did not reveal any statistically significant difference among learners across years of study. The implications of the findings for EFL instructors and learners are discussed
\end{abstract}

Keywords: academic procrastination, Internet use, years of study, EFL.

\section{Introduction}

The Internet plays a crucial role in the access of information resources. In fact, "sources of information and other opportunities available via the Internet are increasing exponentially. This comes with the steady increase in Internet use for education and research" (Edwards \& Bruce, 2002, p.182). The Internet is also an important teaching and learning resource in educational environment if used in a manner appropriate to its aims (Odaci, 2011). With the help of the Internet, students can easily access the materials they need for their studies and obtain information through different ways. However, as with all technologies, in addition to facilitating individuals' lives to a considerable extent, the Internet also brings problems with itself; in particular, the improper use of the Internet may create negative effects. To put it more specifically, the Internet provides people with a variety of potentially entertaining distractors such as emailing or chatting with friends and/or family online, as well as access to sports scores, entertainment news, and hobbies (Thatcher, Wertschko, \& Fridghan, 2008).

Odaci (2011) maintained that university students, at a critical time in terms of their social and emotional development, are a potential risk group for Internet dependence. The fact that Internet is a very useful resource for meeting academic purposes of students does not minimize the negative consequences of the Internet or what has been called unhealthy or Problematic Internet Use (PIU). This can soon lead to tasks that the individual needs to complete but are postponed in an unrealistic manner (Lay, 1988).

University students in this way are unable to devote sufficient time to their academic assignments and studies, so they might constantly postpone the tasks they are required to do. This postponement of academic task called 'academic procrastination' is one variant of general procrastination, which can lead to a problem in getting ready for exams, doing assignment, completing projects, etc. In other words, 'academic procrastination' which can also be named as reflection of daily postponement to school life is defined as to delay duties and responsibilities related to school or to save them to the last minutes (Sepehrian \& Jabari Lotf, 2011).

As such, the Internet can be considered as a tool for procrastination in that it provides an environment where all features contributing to the maintenance of a procrastination field are present to the user. In fact, the Internet developers place the user at risk for procrastination. As such, an atmosphere facilitating time wasting is heightened with the illusion of 
Internet productiveness and efficiency. People with PIU, typically spend a substantial amount of time on non-workrelated Internet activities, and consequently neglect other social or vocational obligations (Timothy \& Potenza, 2007). Generally speaking, the use of the Internet has noticeably increased in society and among university students, and it is widely acknowledged that the Internet has a negative effect on university students' lives (Odaci, 2011). Furthermore, today procrastination is a very common phenomenon among students than ever, especially undergraduates who are shown to frequently exhibit procrastinatory behavior toward their academic tasks such as preparing their homework, studying and also preparing for exams (Sirin, 2011). In spite of the existence of a number of studies (Gafni \& Deri, 2012; Odaci, 2011; Sirin, 2011; Solomon \& Rothblum, 1984; Suhail \& Bargeez, 2006) which focused on how university students use the Internet for academic purposes and how procrastination affects their academic performance, to date no study has been conducted in Iran in order to explore the relationship between academic procrastination and Internet use by Iranian undergraduate EFL learners.

Accordingly, the present study aims to investigate, whether or not Internet use can be a predictor of academic procrastination across years of study. To this end, the following research questions and hypotheses are addressed in this study:

Research question 1: Is there any statistically significant relationship between Internet use and academic procrastination of EFL learners?

Research question 2: Are there any statistically significant differences in the use of the Internet and the extent of procrastination among EFL learners across years of study (freshmen, sophomores, juniors, and seniors?)

Research question 3: What are the differences among EFL learners in different years of study in terms of the areas of academic procrastination and the degree they find it problematic in a given area?

$\mathrm{H}_{0} 1$ : There are no statistically significant relationship between Internet use and academic procrastination of EFL learners.

$\mathrm{H}_{0} 2$ : There are not any differences in the use of the Internet and the extent of procrastination among EFL learners across years of study (freshmen, sophomores, juniors and seniors).

$\mathrm{H}_{0} 3$ : There are no differences among students in different years of study in terms of areas of academic procrastination and the degree they find it problematic in a given area.

\section{Review of Literature}

The field of PIU encompasses situations in which excessive use of the Internet results in dysfunction and pathology (Young \& de Abreu, 2011; cited in Breems \& Badsen, 2013). PIU or staying online for long hours can lead to an unrealistic postponement of the tasks that the individual needs to complete (Lay, 1988). Moreover, Procrastination is the inclination to put off or delay activities. It has also been regarded as "delaying task completion to the point of experiencing subjective discomfort" (Ferrari, 1992, p. 315). Academic procrastination has been regarded as a unique outlet of procrastinatory inventory, and not much scientific research has been conducted on this subject. Tuckman (2002, p. 2; cited in Hannok, 2011) defined academic procrastination as "a dispositional trait that can have particularly serious consequences for students, whose lives are characterized by frequent deadlines".

Solomon and Rothblum (1984) examined the frequency of college students' procrastination for doing academic tasks and their reasons for this procrastinatory behavior. Procrastination on several specific academic tasks was reported as a problem by a high percentage of students. The results of the factor analysis conducted on reasons for procrastination demonstrated that the factors including aversiveness of the task and fear of failure were the causes of most of the variance. In addition, the results exhibited that procrastination should not be regarded solely as a deficit in time management or study habits, but it must be noticed that procrastination involves a complex interaction of affective, cognitive, and behavioral components.

The nature of procrastination via Internet use was examined by Lavoie (2000). Being part of an ongoing research project, information gained from survey respondents was included in the study. A self-report research questionnaire was completed by the participants. The questionnaire composed of 48 questions divided into five sections, including demographic information, participants' personal feeling and attitudes toward the Internet, Internet Time Use Evaluation, General Procrastination (GP) Scale adopted from Lay (1986), and Diener and Emmon's (1985) Composite Affect Scale. The findings illustrated that there was a positive relationship between Internet procrastination and the perception of the Internet as an important tool. It was also shown that the participants were able to better justify online procrastination, since they were interacting with information and regarded the distracting activity as valuable. Ultimately, the study pointed out that Internet procrastination is a significant habit developing in accordance with the growth of the Internet. McCown and Roberts' (1994) study on procrastination across different educational levels revealed that $23 \%$ of freshmen, $27 \%$ of sophomores, $32 \%$ of juniors, and $37 \%$ of seniors had a tendency to procrastinate and the students believed that this behavior had a detrimental effect on their academic achievement. A further interesting finding of their study was that over the years in university life, the degree of procrastination increases.

In a further study, Lavoie and Phychyl (2001) explored the specific relationship between procrastination and Internet use. Data were collected using an online survey. The results indicated that more than half of the respondents acknowledged regular procrastination as a problem while being online, with $47 \%$ online time being procrastinatory in nature. Internet procrastination was shown to be positively correlated with the perception of the Internet as being entertaining and as a kind of relief from pressure. A positive correlation was also reported to exist between Internet procrastination, trait procrastination, and negative emotions.

Al-Maashani (2005) examined the relationships between Internet usage factors including affection and perception towards the Internet, and students' academic performance. The participants were 373 students (217 males and 156 females) who were randomly selected from universities in Oman. The results of the study revealed that Internet usage 
factors strongly correlated with students' academic performance. The study also investigated whether gender makes a difference with regard to these factors. The findings indicated that Internet usage factors differed across gender and it also showed that males were more inclined to use the Internet than females.

Thatcher, Wretscho and Fridjhon (2008) explored whether there was a theoretical and practical overlap between online procrastination and PIU by distributing the Problematic Internet Use Questionnaire (PIUQ) and the distraction subscale of the Online Cognition Scale (OCS) among a sample of 1399 Internet users. A strong positive relationship was found to exist between PIU and online procrastination.

Moreover, Ozer, Demir and Ferrari (2009) explored the prevalence of and reasons for academic procrastination as a function of academic grade level and gender. The study comprised of 784 students (including 363 women, 421 men; $M$ age $=20.6$ years, $S D$ age $=1.74$ years) who completed the Turkish Procrastination Assessment Scale-Students. The findings showed that frequent academic procrastination was reported by $52 \%$ of the participants; this was the case with male students reporting more frequent procrastination on academic tasks compared to female students. Furthermore, the findings illuminated that students procrastinated more while studying for exams (33\%), writing term papers (30\%), and reading assignments $(30 \%)$ than they did in some other academic areas. More specifically, the study reported that more female students than male students believed that the reasons for academic procrastination include fear of failure and laziness. Risk-taking and rebellion against control were also reported as reasons for academic procrastination by male students. Generally, the results illustrated that more than half of the university students always or nearly always procrastinate in their academic tasks.

\section{Methodology}

\subsection{Participants}

As the present study required a pilot study, there were several participants taking part in its different phases. The participants of the pilot study were 30 students among a representative sample of EFL learners at the University of Guilan. It is worth mentioning that all the participants were undergraduates. There were 16 males and 14 females in the pilot study with their age ranging from 18 to 30 .

The participants of the main study consisted of 380 students. They were all undergraduate male $(\mathrm{N}=129)$ and females $(\mathrm{N}=251)$ studying in either English Language and Literature or Translation at the University of Guilan, Kharazmi University and Ferdowsi University. The participants' age ranged from 18 to 28 with the average age of 23 . There were 105 freshmen, 92 sophomores, 95 juniors, and 88 seniors participating in the present study.

\subsection{Instruments}

\subsubsection{Questionnaire}

The main instrument used in the current study was a questionnaire (see the appendix) which consists of several sections. The first part contains information regarding the topic of research and also instructions on how to complete the questionnaire. The second part consists of four biographical questions including gender, age, year of study, and field of study. There is also one question about the duration of using the Internet, and two further questions related to the time spent using the Internet for both general and academic purposes.

To put it more specifically, Section A of the questionnaire was adopted from the study of McCloskey (2011), and it comprised of 25 items assessing students' habits and routines with the aim of exploring the degree of students' academic procrastination. Section B which was adopted from Solomon and Rothblum (1984) was an attempt to rate the degree to which students procrastinated in doing their academic tasks, including three questions regarding each of the following: writing a term paper, studying for exams, keeping up with their weekly reading assignments and also tasks related to making an appointment and meeting their advisor. It needs to be pointed out that after piloting the questionnaire, the part related to 'academic administrative tasks' in Solomon and Rothblum's questionnaire was omitted as it did not apply to the Iranian EFL context. In fact, Section B aimed to assess the degree to which students procrastinated in the aforementioned areas, the degree to which procrastination in those areas is problematic for them and also the extent to which they want to reduce their problem. Finally, Section $C$ was designed particularly for examining the relationship between Internet use and academic procrastination. This section was prepared using different sources such as the Problematic Internet Use Questionnaire (PIUQ) by Thatcher and Goolam, (2006; as cited in Wretschko, 2006), Distraction Subscale of the Online Cognition Scale (OCS) developed by Davis, Flett and Bress (2002; ibid.), Self-report (Flow) Scale adopted and expanded by Webster and Ryan (1933; ibid.), and Solomon and Rothblum's (1984) Procrastination Assessment Scale for Students. The items of all questionnaires were merged with each other and after piloting, ten items were finalized to be included in it.

\subsection{Procedure}

The first step in doing the present study was reviewing related literature to discern the most important issues regarding the topic. The second step was to develop a valid and reliable instrument to find the probable relationship between Internet use and academic procrastination in the Iranian academic context. The validation process of the instrument was done through conducting a pilot study and consultation with experts in the field.

In fact, the pilot study was carried out to examine the feasibility of the questionnaire in order to check the length, layout, and item sequence of the questionnaire as well as to find the reliability and validity of it. During the administration of the questionnaire to 30 students studying at the University of Guilan, the researchers was present while distributing the questionnaire in order to answer any questions or ambiguities which the respondents could have faced. Besides, the needed descriptions were included in the questionnaire. The completion of the questionnaire took about ten minutes for each participant. In this phase of the research, valuable feedback was received based on which one section of the questionnaire was omitted, and two sections were combined in order to make the questionnaire shorter, 
since it was shown to be too long. It should also be noted that a section was provided in the initial questionnaire so that the students could write their ideas to improve the instrument.

Based on the feedback received from the pilot study, the researchers could normally have a near-final version of the questionnaire that seemed satisfactory and that did not have any obvious defect. In the next step, the researchers asked three knowledgeable professors to go through the items of the questionnaire and provide feedback for its content validity.

In the final step, after applying the feedback and making the necessary amendments, the final questionnaire was prepared and administered to students from University of Guilan, Kharazmi University and Ferdowsi University. Regarding the students in the University of Guilan, the questionnaires were distributed by the researcher and with respect to the participants in Kharazmi University and Ferdowsi University, two friends who were also majoring in TEFL at the M.A level were asked to help. The assistants were debriefed about the purpose of the questionnaire and were asked to explain its aim to the participants while distributing them. In addition, all the participants were assured about the anonymity and confidentiality of their responses, and it was tried to clarify any ambiguities raised by them regarding the completion of the questionnaire.

The questionnaires were distributed either before the starting of the class or at the end of the class. The instructions were provided in the participants' first language i.e. Persian, before embarking on filling the questionnaire.

3.4 Data analysis

Data analysis for the present study was done for two phases, namely the pilot study and the main study.

3.4.1 Quantitative and qualitative analysis of data in the pilot study

Regarding the pilot study which aimed to check the reliability and validity of the questionnaire, PASW (SPSS version 18) software was used in order to calculate Cronbach's alpha internal consistency reliability of the questionnaire. The following tables show the results of the reliability analysis:

Table 1. Reliability Statistics for Section A of the Questionnaire

\begin{tabular}{ccc}
\hline Cronbach's Alpha & $\begin{array}{c}\text { Cronbach's Alpha } \\
\text { Based on Standardized items }\end{array}$ & N of items \\
\hline .908 & .907 & 25 \\
\hline
\end{tabular}

Table 2. Reliability Statistics for Section B of the Questionnaire

\begin{tabular}{cccc}
\hline Cronbach's Alpha & $\begin{array}{c}\text { Cronbach's Alpha } \\
\text { Based on Standardized items }\end{array}$ & N of items & Sections \\
\hline .720 & .714 & 3 & 1 \\
.741 & .739 & 3 & 2 \\
.876 & .879 & 3 & 3 \\
.633 & .675 & 3 & 4 \\
\hline
\end{tabular}

Table 3. Reliability Statistics for Section C of the Questionnaire

\begin{tabular}{ccc}
\hline Cronbach's Alpha & $\begin{array}{c}\text { Cronbach's Alpha } \\
\text { Based on Standardized items }\end{array}$ & N of items \\
\hline .813 & .808 & 13 \\
\hline
\end{tabular}

As it is indicated in the tables, for all the three major sections of the questionnaire Cronbach's Alpha is acceptable.

The data gathered from the pilot study were submitted to statistical analysis to fine-tune and finalize the questionnaire. Three aspects of the response pattern were checked: (a) missing responses and possible signs that the instructions were not understood correctly; (b) the range of the responses elicited by each item to identify the items requiring to be excluded since they were endorsed by almost everyone and such a decision is difficult, if not impossible, to be processed statistically; and (c) the internal consistency by which the items that did not work were excluded.

Regarding the content validity of the questionnaire, as explained before, three experts who were also experienced university professors in the field of TEFL were asked to read it and share their ideas as to the appropriateness of the items in the questionnaire.

3.4.2 Quantitative analysis of data in the main study

First of all, for each item in the questionnaire a score was given to each of the scales as follows: Rarely $=1$, Occasionally $=2$, Sometimes $=3$, Often $=4$, and Always $=5$. Using the total and mean scores generated, the data was subjected to further statistical analysis. In order to answer the research questions in this study, Spearman Rank Order Correlation and Kruskal Wallis Test were run on the results of the questionnaire using SPSS 22.

\section{Results}

\subsection{Results of Spearman Rank Order Correlation}

To provide answer to the first research question, namely is there any statistically significant relationship between Internet use and academic procrastination of EFL learners? We hypothesized that there are no statistically significant relationship between Internet use and academic procrastination of EFL learners. To test the null hypothesis, Spearman Rank Order Correlation Test was run to the results of the questionnaire (parts A and C). The output generated from this procedure (Spearman results) is presented in Table 4 below. 




**. Correlation is significant at the 0.01 level (2-tailed).

SPSS output provided a table giving the correlation coefficient between the degree of students' academic procrastination and their Internet use, the significance level and the number of cases. Spearman rho value (+.472) was positive, indicating a positive correlation between the degree of students' academic procrastination and their Internet use. This value indicated the strength of the relationship between the two variables. The more participants used the Internet, the more the degree of students' academic procrastination was. The results of the Spearman Rank Order were interpreted based on Cohen's classification. Cohen (1988, pp. 79-81) suggested the following guidelines for interpreting the results of the correlation coefficient:

Table 5. Cohen's Guidelines for Interpreting the Results of the Correlation Coefficient

\begin{tabular}{ll}
\hline Interpretation & Correlation value \\
Small $\mathbf{r}$ & .10 to .29 \\
Medium r & .30 to .49 \\
Large $\mathbf{r}$ & .50 to 1.0 \\
\hline
\end{tabular}

The above guidelines were applied to interpret the rho value found in the present study. There was a medium correlation between the two variables (rho=.472 $\leq .5$ ), suggesting medium relationship between the degree of students' academic procrastination and their Internet use.

4.1.2 Calculating the Coefficient of Determination

To get an idea of how much variance the two variables shared, the coefficient of determination was calculated. The rho value was squared and then converted to percentage of variance; it was then multiplied by 100 . In this study, the participants' degree of academic procrastination and their Internet use correlated (rho=.47) share (22.09) percent of their variance. Thus, there was an acceptable overlap between the two variables. This means that the participants' degree of Internet use helps to explain nearly 22.09 percent of the variance in respondents' degree of academic procrastination. Therefore, a medium, positive correlation was shown between the two variables, (rho $=+.47, \mathrm{n}=380, \mathrm{p} \leq .01$ ). This rejected the first null hypothesis suggesting that there was a significant correlation between Internet use and academic procrastination of the participating EFL learners. The following figure further depicts the correlation between the degree of students' academic procrastination and their Internet use.

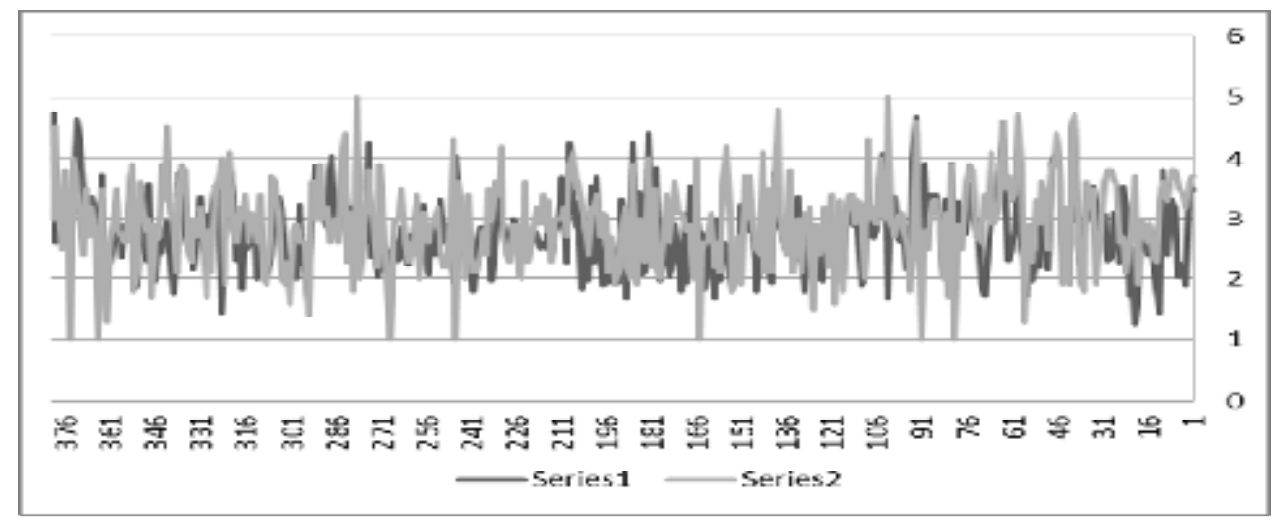

Figure 1. The Correlation between the Degree of Students' Academic Procrastination and Their Internet Use

\subsection{Results of Kruskal Wallis Test}

To provide the answer to the second question, that is, are there any statistically significant differences in the use of the Internet and the extent of procrastination among EFL learners across different years of study (freshmen, sophomores, juniors and seniors)?, we hypothesized that there aren't any differences in the use of the Internet and the extent of procrastination among EFL learners across different years of study (freshmen, sophomores, juniors and seniors).

In order to analyze the data to answer the second research question, descriptive statistics as well as two separate Kruskal Wallis Tests, that is, the non-parametric alternative to a One-way ANOVA were run: One for Internet use (as dependent variable) and different years of study (as independent variable with 4 levels), and another Kruskal Wallis Test was run for academic procrastination (as dependent variable) and different years of study (as independent variable with 4 levels). The mean ranks on Internet use and academic procrastination for the four aforementioned groups were computed. The mean rank for each group was compared and the results are illustrated in Table 6: 
Table 6. Descriptive Statistics for the Degree of Students' Academic Procrastination and Internet Use

\begin{tabular}{llllll}
\hline & $\mathrm{N}$ & Mean & Std. Deviation & Minimum & Maximum \\
\hline The degree of students' academic procrastination & 380 & 2.7621 & .63804 & 1.24 & 4.72 \\
Internet use & 380 & 2.9287 & .73081 & 1.00 & 5.00 \\
\hline
\end{tabular}

Table 4.3 represents the results of descriptive statistics for the degree of students' academic procrastination and the participants' Internet use. Values of the mean and standard deviation for the two variables are given. The mean rank for the degree of students' academic procrastination is $2.76\left(\mathrm{X}_{\text {academic procrastination }}=2.76\right)$, that of the Internet use is $2.92(\mathrm{X}$ internet use $=2.92)$. Moreover, the degree of dispersion of the ratings for the 'degree of students' academic procrastination' $(\mathrm{SD}=.63)$ is almost close to the ratings given by the students for the "Internet use" $(\mathrm{SD}=.73)$.

Table 7 indicates the ranks for the degree of the participants' academic procrastination and Internet use.

Table 7. Ranks for the Degree of Students' Academic Procrastination and Internet Use

\begin{tabular}{llll}
\hline \multirow{2}{*}{ Academic procrastination } & Years of Study & $\mathrm{N}$ & Mean Rank \\
& Freshmen & 105 & 207.88 \\
& Sophomore & 92 & 156.88 \\
& Junior & 95 & 197.31 \\
& Senior & 88 & 197.56 \\
\cline { 2 - 4 } Internet use & Total & 380 & \\
& Freshmen & 105 & 216.29 \\
& Sophomore & 92 & 171.16 \\
& Junior & 95 & 185.14 \\
& Senior & 88 & 185.73 \\
\cline { 2 - 4 } & Total & 380 & \\
\hline
\end{tabular}

The reported mean rank for the four groups reveals which of the groups has the highest overall ranking. An inspection of the mean ranks for the groups suggests that with respect to 'the degree of students' academic procrastination', freshmen had the highest mean rank, with the sophomore group reporting the lowest. Afterwards, Kruskal Wallis Test was run to examine whether these rank differences were statistically significant (see table 8).

Table 8. Results of Kruskal Wallis Test for the Degree of Students' Academic Procrastination and Internet Use

\begin{tabular}{lll}
\hline \multicolumn{2}{l}{ Test Statistics $^{\text {a, b }}$} & \\
\hline Chi-Square & 11.982 & Internet use \\
df & 3 & 9.053 \\
Asymp. Sig. & .007 & 3 \\
a. Kruskal Wallis Test & .029 \\
\hline b. Grouping Variable: educational level &
\end{tabular}

Since the significance levels are less than the assumed alpha level (.05), it could be concluded that there was a statistically significant difference in the variables across the four groups.

To put it more specifically, the Kruskal-Wallis Test revealed a statistically significant difference with respect to 'the degree of students' academic procrastination' and 'Internet use' across the four levels (G1, n = 105: Freshmen, G2, n =

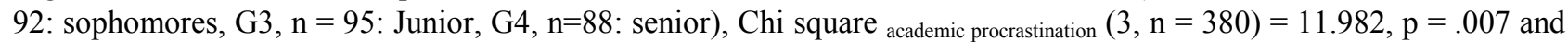
Chi square internet use $(3, \mathrm{n}=380)=9.053, \mathrm{p}=.029)$. These results help us to reject the second null hypothesis and suggest that there are significant differences in the use of the Internet and the extent of academic procrastination among EFL learners across different years of study (freshmen, sophomores, juniors, and seniors).

Considering the third question, that is, the differences among EFL learners of different years of study in terms of the areas of academic procrastination and the degree they find it problematic in a given area, we hypothesized that there are no differences among students in different years of study in terms of areas of procrastination and the degree to which they find it problematic in a given area.

To provide answer for the third research question, descriptive statistics followed by Kruskal Wallis Test were run to the results of section (B) of the questionnaire. It was run to make a comparison of the mean ranks on the degree to which students procrastinated in doing their academic tasks across the four groups. The mean rank for each year of study was computed and compared. The results of this analysis are presented in Table 9.

Table 9. Descriptive Statistics for Different Areas of Procrastination

\begin{tabular}{lccrrr}
\hline \multicolumn{3}{c}{ Descriptive Statistics } & & & \\
\hline & $\mathrm{N}$ & Mean & Std. Deviation & Minimum & Maximum \\
\hline Writing a term paper & 380 & 3.0140 & .95721 & 1.00 & 5.00 \\
Studying for exams & 380 & 3.0632 & 1.05470 & 1.00 & 5.00 \\
Keeping up with weekly reading assignments & 380 & 2.8368 & 1.02775 & 1.00 & 5.00 \\
Attendance tasks & 380 & 2.6877 & 1.06468 & 1.00 & 5.00 \\
\hline
\end{tabular}


Table 9 above represents the results of descriptive statistics for the four areas of academic tasks. Values of the means and standard deviation are given. In general, the mean for "Writing a term paper" amounted to $(\mathrm{X}=3.01)$ that of the "Studying for exams" came to $(\mathrm{X}=3.06)$. Moreover, the mean for "Keeping up with weekly reading assignments" equaled $(X=2.83)$ and for "Attendance tasks" the mean was $(X=2.68)$.

The least degree of dispersion of the ratings was seen for the students' rating of "Writing a term paper" ( $\mathrm{SD}=.95)$. On the contrary, the highest amount of diversity in the respondents' rating was related to "Attendance tasks" ( $\mathrm{SD}=1.06$ ). The Mean Rank for the four groups is presented in Table 10 indicating which group had the highest overall ranking.

Table 10. Ranks of the Four Years of Study with Respect to the Degree to Which Students Procrastinated in Doing Their Academic Tasks

\begin{tabular}{llll}
\hline Ranks & & \\
\hline & Year & N & Mean Rank \\
\hline The degree to which students procrastinated in doing their academic tasks & Freshmen & 105 & 203.00 \\
& Sophomore & 92 & 173.90 \\
& Junior & 95 & 189.46 \\
& Senior & 88 & 194.05 \\
\hline
\end{tabular}

An inspection of the mean ranks for the groups suggests that with respect to "The degree of students' academic procrastination", generally freshmen had the highest mean rank $(X=203.00)$, with the sophomore group reporting the lowest $(\mathrm{X}=173.90)$.

Table 11 ranks the four groups in terms of different areas of the academic procrastination.

Table 11. Ranks of the Four Years of Study with respect to Different Areas of Procrastination

\begin{tabular}{llrr}
\hline \multirow{2}{*}{ Ranks } & & & \\
& Year of Study & N & Mean Rank \\
\hline & Freshmen & 105 & 205.96 \\
& Sophomore & 92 & 179.82 \\
& Junior & 95 & 189.32 \\
& Senior & 88 & 184.49 \\
\cline { 2 - 4 } Studying for exams & Total & 380 & \\
& Freshmen & 105 & 210.87 \\
& Sophomore & 92 & 169.26 \\
& Junior & 95 & 189.36 \\
& Senior & 88 & 189.64 \\
\cline { 2 - 4 } Keeping up with weekly reading assignments & Total & 380 & \\
& Freshmen & 105 & 215.20 \\
& Sophomore & 92 & 169.18 \\
& Junior & 95 & 189.83 \\
& Senior & 88 & 184.03 \\
\cline { 2 - 4 } Attendance tasks & Total & 380 & \\
& Freshmen & 105 & 190.71 \\
& Sophomore & 92 & 188.69 \\
& Junior & 95 & 189.05 \\
& Senior & 88 & 193.71 \\
\cline { 2 - 4 } & Total & 380 & \\
\hline
\end{tabular}

As it is depicted in the above table, the freshmen rated higher than other groups regarding the three areas of the academic tasks including "Writing a term paper", "Studying for exams", and "Keeping up with weekly reading assignments". However, for attendance tasks, the senior group ranked highest.

The following Kruskal Wallis test examined whether the differences in the ranks were statistically significant.

Table 12. Kruskal Wallis Test for the Four Years of Study with Respect to the Degree to Which Students Procrastinated in Doing Their Academic Tasks

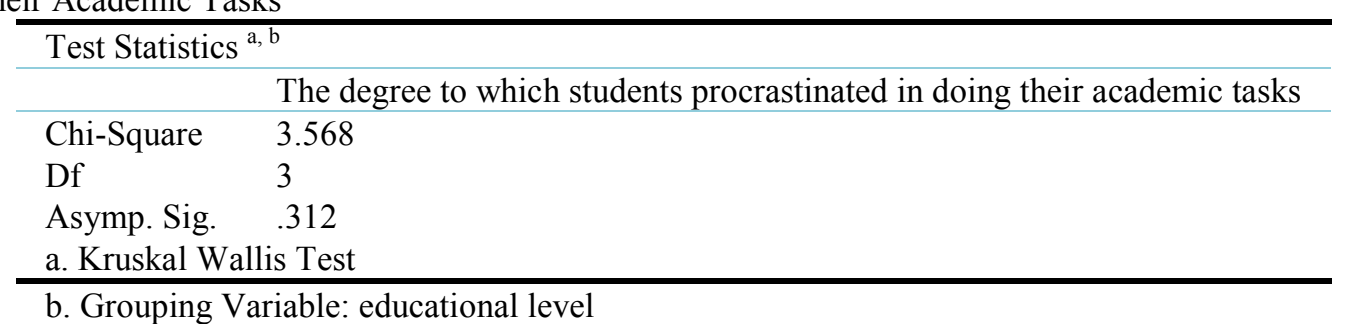

b. Grouping Variable: educational level 
As the significance level was higher than .05 , it could be perceived that in general there was not a statistically significant difference in "the degree to which students procrastinated in doing their academic tasks" across the four groups. Moreover, the findings of Kruskal-Wallis Test showed: (G1, $\mathrm{n}=105$ : Freshmen, G2, $\mathrm{n}=92$ : sophomores, G3, $\mathrm{n}$ $=95$ : Junior, G4, $\mathrm{n}=88$ : senior), Chi square procrastination in doing academic tasks $(3, \mathrm{n}=380)=3.568, \mathrm{p}=.312)$. This finding supports the third null hypothesis and suggested that there were not any differences in "the degree to which students procrastinated in doing their academic tasks" among EFL learners across years of study.

Additionally, another Kruskal Wallis test compared the four groups in terms of different "areas of procrastination". The results are presented in Table 13.

Table 13. Kruskal Wallis Test for the Four Years of Study with respect to Different Areas of Procrastination

\begin{tabular}{lrrrr} 
& \multicolumn{2}{c}{ Test Statistics } & \\
& $\begin{array}{c}\text { Writing a term } \\
\text { paper }\end{array}$ & $\begin{array}{c}\text { Studying for } \\
\text { exams }\end{array}$ & $\begin{array}{c}\text { Keeping up with weekly reading } \\
\text { assignments }\end{array}$ & $\begin{array}{c}\text { Attendance } \\
\text { tasks }\end{array}$ \\
Chi-Square & 3.261 & 7.137 & 9.180 & .119 \\
Df & 3 & 3 & 3 & .027 \\
Asymp. & .353 & .068 & .989 \\
Sig. & & & & 3 \\
a. Kruskal Wallis Test & & & &
\end{tabular}

As depicted in the above output, the p-values of three areas of the academic task namely "Writing a term paper", "Studying for exams", and "attendance tasks" were all higher than .05 indicating that the difference in these areas were not significant across the four groups. However, for the third area of the academic task, that is "Keeping up with weekly reading assignments", the difference among the four levels was statistically significant. [Chi-square Keeping up with weekly reading assignments $(3, \mathrm{n}=380)=9.18, \mathrm{p}=.027)]$.

The following table present the results for the degree to which procrastination in each area is a problem for the learners across years of the study.

Table 14. Ranks of the Four Years of the Study with respect to the Degree They Find It Problematic in a Given Area

\begin{tabular}{|c|c|c|c|}
\hline Ranks & & & \\
\hline & $\begin{array}{l}\text { educational } \\
\text { level }\end{array}$ & $\mathrm{N}$ & $\begin{array}{l}\text { Mean } \\
\text { Rank }\end{array}$ \\
\hline \multirow[t]{5}{*}{ To what degree is procrastination on writing a term paper a problem for you? } & Freshmen & 105 & 201.69 \\
\hline & Sophomore & 92 & 183.35 \\
\hline & Junior & 95 & 195.21 \\
\hline & Senior & 88 & 179.55 \\
\hline & Total & 380 & \\
\hline \multirow[t]{5}{*}{ To what degree is procrastination on studying for exams a problem for you? } & Freshmen & 105 & 209.80 \\
\hline & Sophomore & 92 & 169.35 \\
\hline & Junior & 95 & 194.12 \\
\hline & Senior & 88 & 185.69 \\
\hline & Total & 380 & \\
\hline \multirow{5}{*}{$\begin{array}{l}\text { To what degree is procrastination on keeping up with weekly reading } \\
\text { assignments a problem for you? }\end{array}$} & Freshmen & 105 & 176.83 \\
\hline & Sophomore & 92 & 174.26 \\
\hline & Junior & 95 & 201.09 \\
\hline & Senior & 88 & 212.35 \\
\hline & Total & 380 & \\
\hline \multirow[t]{5}{*}{ To what degree is procrastination on attendance tasks a problem for you? } & Freshmen & 105 & 191.18 \\
\hline & Sophomore & 92 & 193.85 \\
\hline & Junior & 95 & 189.44 \\
\hline & Senior & 88 & 187.34 \\
\hline & Total & 380 & \\
\hline
\end{tabular}

As it is depicted in the above table, the participants of the freshmen group rated higher than other groups with respect to the degree that they find procrastination problematic in two areas of the academic tasks including "Writing a term paper", and "Studying for exams". However, for the degree they find it problematic in "Keeping up with weekly reading assignments," the senior group ranked higher than the other three groups. Moreover, for the degree that the students find it problematic in "attendance tasks", sophomores' ratings were the highest. The following Kruskal Wallis test examined whether the differences in the ranks were statistically significant. 
Table 15. Kruskal Wallis Test for the Four Years of the Study with respect to the Degree They Find it Problematic in a Given Area

\begin{tabular}{|c|c|c|c|c|}
\hline \multicolumn{5}{|c|}{ Test Statistics ${ }^{a, b}$} \\
\hline & $\begin{array}{l}\text { To what degree is } \\
\text { procrastination on } \\
\text { writing a term paper a } \\
\text { problem for you? }\end{array}$ & $\begin{array}{l}\text { To what degree is } \\
\text { procrastination on } \\
\text { studying for exams a } \\
\text { problem for you? }\end{array}$ & $\begin{array}{l}\text { To what degree is } \\
\text { procrastination } \\
\text { keeping up with weekly } \\
\text { reading assignments a } \\
\text { problem for you? }\end{array}$ & $\begin{array}{l}\text { To what degree is } \\
\text { procrastination on } \\
\text { attendance tasks a } \\
\text { problem for you? }\end{array}$ \\
\hline $\begin{array}{l}\text { Chi- } \\
\text { Square }\end{array}$ & 2.668 & 7.263 & 8.445 & .180 \\
\hline $\mathrm{df}$ & 3 & 3 & 3 & 3 \\
\hline $\begin{array}{l}\text { Asymp. } \\
\text { Sig. } \\
\text { a. Krusk }\end{array}$ & $\begin{array}{l}.446 \\
\text { Nallis Test }\end{array}$ & .064 & .038 & .981 \\
\hline
\end{tabular}

b. Grouping Variable: educational level

As it is illustrated in the above output, the (p) values for the degree the participants of the four groups find it problematic in three areas of the academic task namely "Writing a term paper", "Studying for exams", and "attendance tasks" were all higher than (.05). These indicate that the difference in the degree they find it problematic in these areas were not statistically significant across the four years of the study. But, for the degree they find it problematic in the third area of the academic task, that is "Keeping up with weekly reading assignments", the difference was statistically significant. Chi -square $\left.{ }_{\text {Keeping up with weekly reading assignments }}(3, \mathrm{n}=380)=8.44, \mathrm{p}=.038\right)$.

\section{Discussion and Conclusion}

Considering the outstanding growth of Internet use among university students and the prevalence of academic procrastination, the present study aimed at investigating the probable relationship between Internet use and academic procrastination of a group of Iranian undergraduates across four years of study. To fulfill this aim, a piloted questionnaire was distributed among 380 university students comprising freshmen, sophomores, juniors, and seniors studying English language in three universities.

Previous studies on procrastination such as Solomon and Rothblum (1984) mostly considered the frequency of students' procrastinatory behavior or approached procrastination in its broadest terms. In addition, only a few studies have taken into account the relationship between Internet use and academic procrastination. Regarding the first research question in the present study, the results of Spearman rho value at $p \leq .01$ revealed a medium positive correlation as +.472 between the participants' Internet use and academic procrastination. This finding completes the research study conducted by Lavoie (2000) who found a positive relationship between Internet procrastination and its consideration as an important tool. It is also in line with the findings of Lavoie and Pychyl (2001) with the difference that in their study procrastination was regarded in its general sense; however, in the present study we specifically focused on academic procrastination. With respect to the second research question, the findings further indicated that there is a difference between Internet use and academic procrastination of students at different years of study. In fact, the results of Kruskal Wallis Test revealed that a statistically significant difference exists among freshmen, sophomores, juniors and seniors both in terms of academic procrastination $(\operatorname{sig}=.007, p \leq .05)$ and Internet use $(\operatorname{sig}=.029, p \leq .05)$, with freshmen ranking the highest in both and sophomores ranking the lowest. This further supports the results of a study by McCown and Roberts (1994) which showed a differing degree of procrastination across various years of the study with freshmen showing the lowest and seniors revealing the highest degree of academic procrastination.

With regard to the third research question which aimed at examining whether there are differences among EFL learners of different years of study with respect to areas of procrastination and the degree to which they consider it problematic in a given area, the results of Kruskal Wallis Test did not reveal any significant difference across the four groups (sig = $.312, \mathrm{p}>.05)$. In addition, regarding three of the four area of procrastination addressed in the present study, namely, writing a term paper $(\mathrm{sig}=.353, \mathrm{p}>.05)$, studying for exam $(\mathrm{sig}=.063, \mathrm{p}>.05)$ and attendance task $(\operatorname{sig}=.989, \mathrm{p}>.05)$, no significant difference was reported among the four years of study; however, for the area of keeping up with weekly reading assignments $(\operatorname{sig}=.027, \mathrm{p} \leq .05)$, there was shown to be a significant difference among the four groups, with freshmen ranking higher than the other groups. Moreover, concerning the differences among students across years of study in terms of the degree to which they found a given area problematic, the results of Kruskal-Wallis Test revealed that only in one of the areas, i.e. "keeping up with weekly reading assignments" there was a statistically significant difference across the four groups $(\mathrm{p}=.038)$.

Therefore, based on the findings of the present study it can be concluded that there is a moderate relationship between Internet use and academic procrastination of EFL learners who participated in this study and the variable of years of study can be a determining factor in this regard. As such, it can be further inferred that Internet use can be an indicator of academic procrastination of EFL undergraduates.

In light of the findings of this study, procrastinating students, particularly freshmen, can become aware of the probable detrimental effects of their behavior and it is hoped that by appropriate time management and training they would be able to minimize the procrastination which can be caused by PIU. However, further research is needed to probe deeply into other causes of academic procrastination. Moreover, research can be conducted considering other groups of students such as postgraduates. 


\section{References}

Al-Maashani, S. M. M. (2005). Internet usage as a learning tool among undergraduate students in the college of education Salalah Oman. (Unpublished M.A. thesis). International Islamic University, Malaysia.

Breems, N. \& Basden, A. (2014). Understanding of computers and procrastination: A philosophical approach. Computers in Human Behavior, 31, 211-223.

Cohen, J. (1988). Statistical power analysis for the behavioral sciences (2 ${ }^{\text {nd }}$ ed.). New Jersey: Lawrence Erlbaum. Edwards, S. L., \& Bruce, C. S. (2002). Reflective Internet searching: an action research model. The Learning Organization: An International Journal, 9(4), 180-188.

Ferrari, J. (1992). Procrastination in the workplace: Attributions for failure among individuals with similar behavioral tendencies. Personality and Individual Differences, 13(3), 315-319.

Gafni, R. \& Deri, M. (2012). Costs and benefits of Facebook for undergraduate students. Interdisciplinary Journal of Information, Knowledge, and Management, 7, 45-61.

Hannok, W. (2011). Procrastination and motivation beliefs of adolescents: A cross-cultural study. (Unpublished doctoral dissertation). University of Alberta, Edmonton.

Lavoie, J. (2000). Cyber-slacking and the procrastination super highway: An analysis of procrastinatory attitudes, perceptions and affect on the Internet. Honours thesis, Carleton University.

Lavoie, J. A. A., \& Pychyl, T. A. (2001). Cyberslacking and the procrastination superhighway: A web-based survey of online procrastination, attitudes, and emotion. Social Science Computer Review, 19, 431-444.

Lay, C. H. (1988). The relationship of procrastination and optimism to judgments of time to complete an essay and anticipation of setbacks. Journal of Social Behavior \& Personality, 3, 201-214.

McCloskey, J. D. (2011). Finally, my thesis on academic procrastination. (Unpublished M.A. thesis). University of Texas, U.S.

McCown, W.G. and Roberts, R. (1994). A study of academic and work-related dysfunctioning relevant to the college version of an indirect measure of impulsive behavior. Integra Technical Paper, 94-98, Radnor, PA: Integra, Inc.

Odaci, H. (2011). Academic self-efficacy and academic procrastination as predictors of problematic internet use in university students. Computers \& Education, 57(1), 1109-1113.

Sepehrian, F., \& Jabari Lotf, J. (2011). The effect of copying styles and gender on academic procrastination among university students. Journal of Basic \& Applied Scientific Research 1(12), , 2987-2993.

Sirin, E. F. (2011). Academic procrastination among undergraduates attending school of physical education and sports: Role of general procrastination, academic motivation and academic self-efficacy. Educational Research \& Review, 5, 447-465.

Solomon, L. J., \& Rothblum, E. D. (1984). Academic procrastination: frequency and cognitive-behavioral correlates. Journal of Counseling Psychology, 31, 503-509.

Suhail, K., \& Bargees, Z,. (2006). Effect of excessive internet use on undergraduate students in Pakistan. Cyberpsychology \& Behavior, 9(3), 297-307.

Thatcher, A., Wretchko, G., \& Fisher, J. (2008). Problematic internet use among information technology workers in South Africa. CyberPsychology \& Behavior, 11, 785-787.

Timothy, L. \& Potenza, M. N. (2007). Problematic internet use: Clinical implication. Journal CMES, 12(6), $453-466$. Uzun Özer, B., Demir, A., \& Ferrari, J. (2009). Exploring academic procrastination among Turkish students: Possible gender differences in prevalence and reasons. The Journal of Social Psychology, 149(2), 241-257.

Wretschko, G. (2006). Problematic internet use, flow and procrastination in the workplace. (Unpublished M.A Thesis) University of Witwatersrand, Johannesburg.

\section{Appendix \\ Questionnaire}

Dear students:

You are being invited to take part in a research study in the area of procrastination that is a failure to initiate or complete a task or activity by predetermined time. The aim is to explore the nature of Internet use for procrastination by EFL undergraduate students.

Participation in this research will involve completing the following questionnaire, and should take no longer than 20 minutes to complete. Participation is voluntary and your responses will remain confidential. There are (of course) no correct or incorrect answers and the aim is to explore your attitudes only.

If you choose to participate in the study please complete the following questionnaire as carefully and honestly as possible. Your responses will only be used for the purpose of this research.

Thank you for taking the time to consider participating in this study. If you got any questions or new ideas helping to improve the result of this study, please contact me at the following email address:

1. Age:

2. Gender: Male $\square$....................

3. $\quad$ Year of study: Freshmen (1st year) $\square$ Sophomore (2nd year) $\square$ Junior (3rd year ) $\square$ Senior (4th year) $\square$

4. Major: Teaching English $\square \quad$ English Literature

5. How long have you been using the Internet?

Less than 1 year $\square \quad 1-2$ years $\square \quad 2-4$ years $\square \quad$ More than 4 years $\square$ 
6.How many hours on average do you spend in a week to use the Internet for general use (e.g. gaming, shopping, ...) ?

7.How many hours on average do you spend in a week to use the Internet for academic use (e.g. searching for articles, ...)?

Section A: The following questions assess your habits and routines as a student in academic context. Please answer the following as they apply to yourself. How much do you, yourself agree to the following statements? In the box to the right of each statement, fill in the number on the 5 point scale that best describes you.

\section{Always Often Sometimes Occasionally Rarely}

1. I usually allocate time to review and proofread my work.

2. I put off projects until the last minute.

3. I have found myself waiting until the day before to start a big project.

4. I know I should work on assignments, but I just don't do it.

5. When working on assignments, I usually get distracted by other things.

6. I waste a lot of time on unimportant things.

7. I get distracted by other, more fun, things when I am supposed to work on an assignments.

8. I concentrate on assignments instead of other distractions.

9. I can't focus on assignments or projects for more than an hour until I get distracted

10. My attention span for assignments is very short.

11. Tests are meant to be studied for just the night before.

12. I feel prepared well in advance for most tests.

13. "Cramming" and last minute studying is the best way that I study for a big test.

14. I allocate time to regular studying, so I don't have to "cram" at the end of the semester.

15. I only study the night before exams.

16. If an assignment is due at midnight, I will work on it until 11:59.

17. When given an assignment, I usually put it away and forget about it until it is almost due

18. Friends usually distract me from assignments.

19. I find myself talking to friends or family instead of working on school work.

20. On the weekends, I make plans to do assignments and projects, but I get distracted and hang out with friends.

21. I tend to put off things for the next day.

22. I don't spend much time studying textbooks until the end of the semester.

23. I frequently find myself putting important deadlines off.

24. If I don't understand something, I'll usually wait until the night before a test to figure it out.

25. I read the textbook and look over notes before coming to class and listening to a lecture or teacher

\section{Section B:}

\section{Always Often Sometimes Occasionally Rarely}

\section{WRITING A TERM PAPER}

1.To what degree do you procrastinate on this task?

2.To what degree is procrastination on this task a problem for you?

3.To what extent do you want to decrease your tendency to procrastinate on this task?

II. STUDYING FOR EXAMS

4.To what degree do you procrastinate on this task?

5.To what degree is procrastination on this task a problem for you?

6.To what extent do you want to decrease your tendency to procrastinate on this task?

III. KEEPING UP WITH WEEKLY READING ASSIGNMENTS

7.To what degree do you procrastinate on this task?

8.To what degree is procrastination on this task a problem for you?

9.To what extent do you want to decrease your tendency to procrastinate on this task?

IV. ATTENDANCE TASKS: MEETING WITH YOUR ADVISOR, MAKING AN APPOINTMENT WITH A PROFESSOR

10.To what degree do you procrastinate on this task?

11.To what degree is procrastination on this task a problem for you?

12.To what extent do you want to decrease your tendency to procrastinate on this task?

\section{Section C:}

\section{Always Often Sometimes Occasionally Rarely}

1-I need to use the Internet for increased amounts of time in order to achieve academic success.

2-When I am online I don't think about my responsibilities.

3. When using the internet, I was aware of distractions.

4. I often use the Internet for recreational purposes while online for doing academic work.

5. I don't pay attention to advantages time when using the Internet.

6 . I often use the Internet to avoid doing my academic assignment.

7. Using the Internet is a way to procrastinate about my academic work.

8. I often prefer the excitement of the Internet to doing my academic assignment.

9. I sometimes use the Internet to procrastinate.

10. I feel the need to use the Internet for my academic assignments. 